\title{
Escape behavior of planktonic copepods in response to hydrodynamic disturbances: high speed video analysis
}

\author{
E. J. Buskey ${ }^{1, *}$, P. H. Lenz ${ }^{2}$, D. K. Hartline ${ }^{2}$ \\ ${ }^{1}$ Marine Science Institute, University of Texas at Austin, 750 Channel View Drive, Port Aransas, Texas 78373, USA \\ ${ }^{2}$ Bekesy Laboratory of Neurobiology, Pacific Biomedical Research Center, University of Hawaii at Manoa, 1993 East-West Road, \\ Honolulu, Hawaii 96822, USA
}

\begin{abstract}
Planktonic copepods exhibit rapid escape behavior in response to hydrodynamic disturbances. Small disturbances of brief duration were produced by a piezoelectric transducer moving a small cylinder. The escape responses of free-swimming adult males and females of the copepods Acartia tonsa and A. lilljeborgii were recorded using high-speed video and quantified using computerized motion analysis techniques. Response latency, swimming speed, acceleration and turning rate during escape behavior were measured. Acartia spp. typically respond within $4 \mathrm{~ms}$ to a hydrodynamic disturbance with multiple power strokes of the swimming legs. Each stroke and recovery is of ca. $7 \mathrm{~ms}$ duration with maximum speeds often exceeding $500 \mathrm{~mm} \mathrm{~s}^{-1}$ and minimum speeds between strokes rarely falling below $100 \mathrm{~mm} \mathrm{~s}^{-1}$. Acceleration during initial escape usually exceeds $100 \mathrm{~m} \mathrm{~s}^{-2}$. Escapes often begin with rapid reorientation away from the source of the disturbance, with maximum turning rates of about $30^{\circ} \mathrm{ms}^{-1}$. Significant differences were found between the kinetics of escape responses of adult male and female copepods of each species, with males having greater maximum speeds and accelerations, and females having longer duration jumps. Significant differences were also found between males and females of the 2 species, with A. lilljeborgii exhibiting greater speeds and more rapid acceleration than the smaller $A$. tonsa.
\end{abstract}

KEY WORDS: Copepods · Acartia $\cdot$ Escape behavior $\cdot$ High-speed video $\cdot$ Hydrodynamic stimuli

\section{INTRODUCTION}

Planktonic copepods are consumed by a wide range of predators and are widely recognized as an important trophic link between phytoplankton and other marine organisms. Therefore, adaptations that reduce risk of predation are essential to the survival of these animals in the pelagic environment. Adaptations to reduce predation risk include reduced visibility (Zaret 1972, Kerfoot 1980, Buskey 1994), vertical migration (Russell 1927, Zaret \& Suffern 1976), bioluminescence

*E-mail: buskey@utmsi.utexas.edu
(Young 1983, Herring 1988) and effective escape behaviors (Singarajah 1969, Fields \& Yen 1997b). Species of copepods may have evolved one or more of these anti-predator adaptations, depending on the habitat they live in and the selective pressures they have been exposed to over time. Vertical migration is widespread among species which live in environments with diel or seasonal changes in light intensity that often serve as the proximate cue for these migrations (Forward 1976, Angel 1985). Bioluminescence seems to be most common among copepods that inhabit the disphotic or aphotic zone during the day (Herring 1988), and transparency is often found in copepods that spend their days in well-lit surface waters (Greze 
1963). Effective escape responses appear to be widely distributed among copepod species from a wide range of habitats, however (Lenz et al. 2000).

Because of the rapid acceleration and short duration of copepod escape jumps, accurate quantification of these behaviors requires high temporal resolution. For tethered copepods there have been several recent studies of the reaction times and force production for escape jumps that provide high temporal resolution (e.g. Hartline et al. 1996, 1999, Lenz \& Hartline 1999). These studies have underscored the importance of observing copepod behavior at a temporal resolution of milliseconds. Escape reactions on the tether are initiated within a few milliseconds and powerful escape jumps with multiple thrusts by the swimming legs are completed in less than $50 \mathrm{~ms}$ (Lenz \& Hartline 1999). However there are few quantitative studies of the kinetics of escape behaviors for free-swimming copepods (e.g. Strickler 1975: temporal resolution $4 \mathrm{~ms}$ ). Although force records from tethered copepods have provided data on the motor performance during the escape, it is not clear how this force is translated into actual movement in free-swimming individuals. In the present study, we quantified escape responses to a hydrodynamic stimulus for free-swimming calanoid copepods.

Copepods of the genus Acartia are characteristic of estuarine and neritic environments throughout the world, and A. tonsa is one of the more thoroughly studied species of calanoid copepods in the world (Mauchline 1998). We performed a detailed analysis of the kinetics of the escape behavior of A. tonsa and

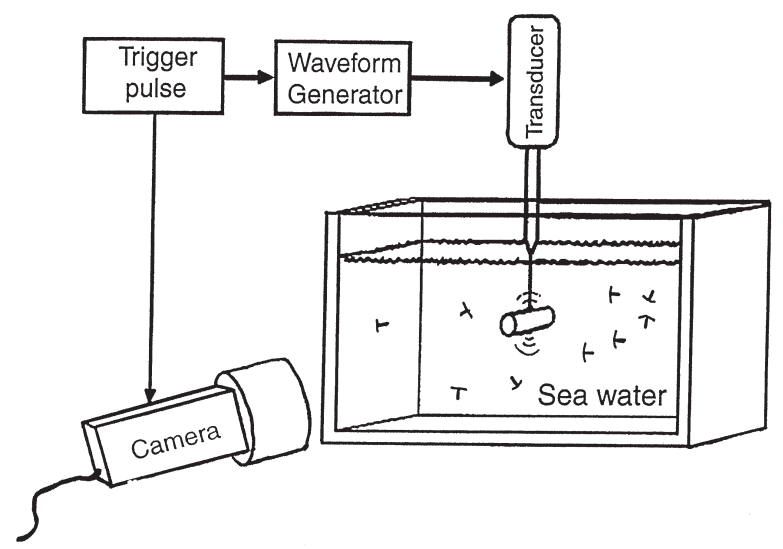

Fig. 1. Experimental set-up. A trigger pulse stimulates a computer-driven waveform generator to drive a piezoelectric transducer which vibrates a plastic cylinder to produce a hydrodynamic disturbance. This same pulse stimulates the high-speed video camera to capture a ca. $2.2 \mathrm{~s}$ sequence centered around the stimulus. Escape responses of copepods freely swimming in the clear acrylic aquarium are recorded. Diagrammatic (not to scale)
A. lilljeborgii using high-speed video (1000 frames $\mathrm{s}^{-1}$ ) and computerized motion-analysis. Escape reactions were stimulated by slight movements of a small cylinder. These movements elicited escape responses in free-swimming copepods. Stimulus strength can be calculated at known distances from the cylinder, allowing for estimation of sensitivity to hydrodynamic stimuli.

\section{MATERIALS AND METHODS}

Copepods for this study were collected by streaming a $0.5 \mathrm{~m}$ diameter, $153 \mu \mathrm{m}$ mesh plankton net with the tidal current from the University of Texas Marine Science Institute pier located in the Aransas Ship Channel between the Gulf of Mexico and Aransas Bay. The contents of the cod end of the plankton net were diluted with whole seawater in a plastic bucket and returned to the laboratory for sorting. Adult Acartia tonsa and A. lilljeborgii were isolated from the sample using a large-bore pipette; males and females were collected separately and held in groups of 10 in $50 \mathrm{ml}$ glass beakers containing filtered seawater. Additional copepods were collected, anesthetized with MS-222, and their total length, prosome length and maximum prosome width were measured.

Ten adult copepods of the same species and sex were gently poured from the beakers into a small plastic aquarium constructed of clear acrylic plastic with inside dimensions of $2.3 \times 8 \times 4 \mathrm{~cm}$. Filtered seawater was added to bring the water level to a consistent height $(3.5 \mathrm{~cm})$. The chamber was then placed on a platform resting on a vibration isolation bench top (Newport, Model BT-2024). A small plastic cylinder (3 $\mathrm{mm}$ diameter, $2 \mathrm{~cm}$ in length) connected by a stainless steel rod to a piezo electric pusher was lowered into the chamber and situated in the middle of the water column, approximately $1 \mathrm{~cm}$ from one end of the chamber and spanning its width $(1.5 \mathrm{~mm}$ clearance on each end) (Fig. 1). The copepods were then allowed to acclimate for $30 \mathrm{~min}$ before testing.

The hydrodynamic stimulus was produced by the vertical movement, under computer control, of the plastic cylinder. The stimulus wave form used was 1.5 cycles of a $700 \mathrm{~Hz}$ sine-wave multiplied by a trapezoidal function which rose linearly for 0.4 cycle, stayed constant for 0.7 cycle and then decreased linearly to zero in the final 0.4 cycle. This form was designed to provide a brief displacement returning to its initial position, without abrupt transitions in slope (Gassie et al. 1993). The peak-to-peak excursion of the cylinder was $34.4 \mu \mathrm{m}$, with peak velocities of $88 \mathrm{~mm} \mathrm{~s}^{-1}$, generating peak Reynolds numbers around 260. A cylinder moving in an incompressible invicid fluid produces a 
2-dimensional dipole doublet flow, the velocity components of which in polar coordinates are (e.g. Kundu 1990, p. 155):

$$
\begin{aligned}
& u_{\mathrm{r}}=a^{2} U \cos (\theta) / \mathrm{r}^{2} \\
& u_{\theta}=a^{2} U \sin (\theta) / \mathrm{r}^{2}
\end{aligned}
$$

for a cylinder of radius a moving with velocity $U$ in the $\theta=0$ direction. The flow-field generated is a series of circular stream lines tangent to the axis of cylinder movement at the cylinder center. Since the sensory apparatus of free-swimming copepods appears to detect only water movement relative to the copepod itself (Haury et al. 1980, Yen et al. 1992, Kiørboe et al. 1999), the effective stimulus depends on the deformation of the fluid immediately surrounding the copepod. To the extent that Eq. (1) holds true, this can be computed from the components of the rate-of-strain tensor (e), as outlined by various authors (e.g. Batchelor 1967 , Kiørboe \& Visser 1999):

$$
\begin{gathered}
e_{\mathrm{rr}}=\partial u_{\mathrm{r}} / \partial r=k \cos (\theta) \\
e_{\theta \theta}=(1 / r) \partial u_{\theta} / \partial \theta+u_{\mathrm{r}} / r=-k \cos (\theta) \\
e_{\mathrm{r} \theta}=e_{\theta \mathrm{r}}=(r / 2) \partial / \partial r\left(u_{\theta} / r\right)+(1 / 2 r) \partial u_{\mathrm{r}} / \partial \theta=k \sin (\theta)
\end{gathered}
$$

where $k \equiv-2 a^{2} U / r^{3}$. In this tensor,

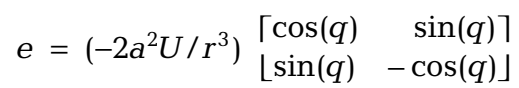

The matrix in brackets represents a vector rotation of angle $\theta$ about the origin. Hence the deformation rate, $\Delta$, is independent of angle with respect to cylinder movement and varies inversely with the cube of the distance from the center (Haury et al. 1980):

$$
\Delta=-2 a^{2} U / r^{3}
$$

We can apply these equations to each instant of time during the generation of the stimulus, but in particular to the instant of maximum velocity of cylinder movement (zero-crossing of displacement). Because the movement is very brief and small, we are able to ignore boundary layers and the build-up of vortices (e.g. Kundu 1990, p. 323).

Images of copepod escape responses were recorded at 1000 frames $\mathrm{s}^{-1}$ using a high-speed video camera (Kodak Motion Corder Analyzer Model SR-3000). The camera was equipped with a $50 \mathrm{~mm}$ f1.4 Nikon Nikkor lens, and viewed an area of ca. $25 \times 30 \mathrm{~mm}$ to one side of the stimulus cylinder. White light at ca. $150 \mu \mathrm{M} \mathrm{m}^{-2}$ $\mathrm{s}^{-1}$ was provided by a fiber optic light. This light tended to attract copepods to the field of view of the video camera, and within a few $\mathrm{mm}$ of the stimulus. Additional lighting was provided by a dark-field array of infrared light-emitting diodes to provide increased light to compensate for the short exposure time of each frame. The high-speed video camera recorded 2184 frames of video at 1000 frames $\mathrm{s}^{-1}$. A personal com- puter provided the signal to drive the piezo electric pusher to produce the defined stimulus; this same signal was used to trigger the camera to capture half the video frames before and half after the stimulus. These frames were then played back at 30 frames $\mathrm{s}^{-1}$ and recorded on a Panasonic AG 6300 video cassette recorder.

The stimulus was activated when 1 or more copepods were positioned near the cylinder. After each stimulation, the video was reviewed at slower speed and examined frame by frame for approximately $30 \mathrm{~ms}$ after the stimulus. The response latency in $\mathrm{ms}$ was recorded for those copepods responding to the stimulus. The video was then paused on an image captured a few ms after the stimulus. Positions of copepods, both responding and not responding to the stimulus, were drawn on an acetate sheet placed over the monitor screen, noting their orientation with respect to the stimulus and the location of their antennae. These records were used to calculate the proportion of copepods responding at various distances from the stimulus, and it allowed the orientation of copepods at the time of the stimulus to be tabulated.

These high-speed video records were then reviewed to choose escape paths for computerized motion analysis. Since escape behaviors were recorded in 2 dimensions, only those copepods with escape jumps perpendicular to the recording camera will accurately record trajectories. To minimize errors through analysis of paths not perpendicular to the camera, the aspect ratios of copepod images were measured at the beginning, middle and near the end of their escape jumps. Aspect ratios $>3$ indicated that a copepod was perpendicular to the line of view of the video camera. Escape responses with an aspect ratio $<2.5$ during part of their trajectory were not used for motion analysis. A minimum of 50 paths were quantified for escape responses of adult males and females of each species. For comparative purposes, 20 spontaneous jumps from adult female Acartia tonsa were also analyzed.

Swimming behavior of the copepods was quantified from videotapes using an Expertvision Cell-Trak video-computer motion analysis system. High speed video recorded at 1000 frames $\mathrm{s}^{-1}$ had been transferred to videotape at 30 frames $\mathrm{s}^{-1}$. These videotaped images of the copepods were digitized using the Motion Analysis VP-110 video-to-digital processor, and digitized outlines of the copepods were sent to a host computer at a rate of 30 frames $\mathrm{s}^{-1}$. These digitized images were processed to calculate the swimming speeds $\left(\mathrm{mm} \mathrm{s}^{-1}\right)$, acceleration $\left(\mathrm{mm} \mathrm{s}^{-2}\right)$, jump duration (ms), total distance jumped (mm) and number of swimming leg thrusts per jump of the copepods' paths of travel using Cell-Trak software. 

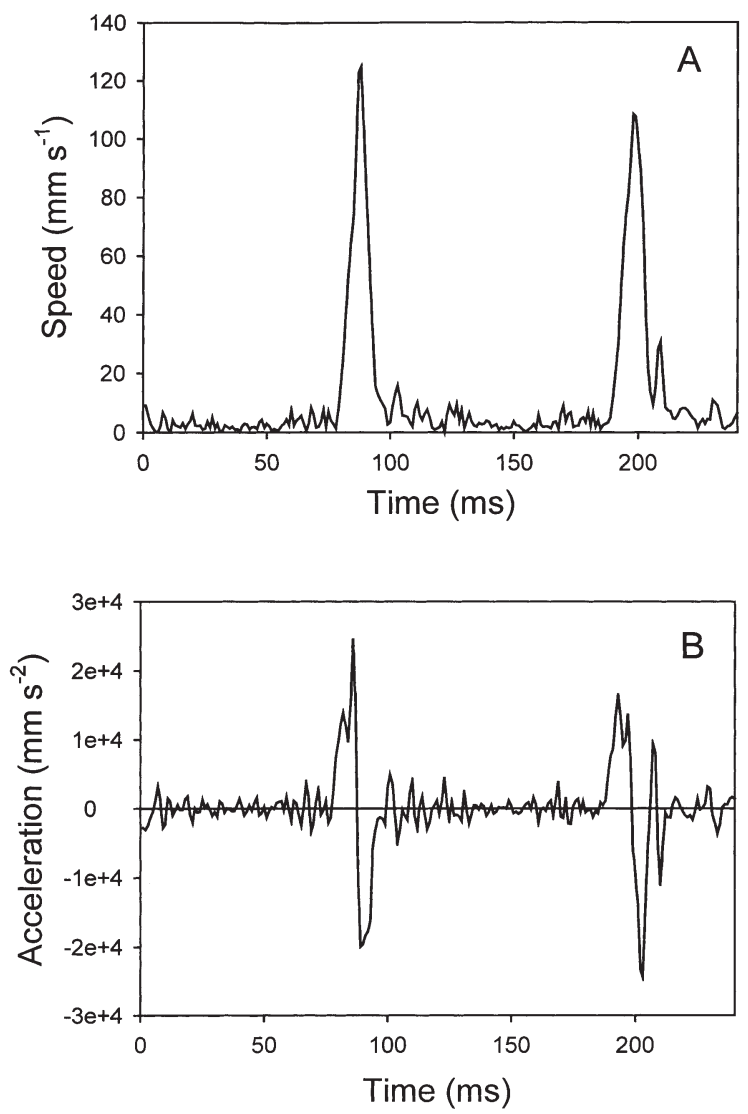

Fig. 2. Acartia tonsa. Example of (A) speed and (B) acceleration records for 2 representative spontaneous 'hops' of adult male. Most of the small peaks before and between the jumps are noise resulting from the high temporal resolution of the video (1000 frames $\left.\mathrm{s}^{-1}\right)$ used in the automated motion analysis

Jump latencies (time from stimulus to response) were determined by reviewing the videotapes frameby-frame. Copepods often began their escape responses with a rapid (1 to $2 \mathrm{~ms}$ ) reorientation of their bodies before leaping away. The extent of these initial turns was also determined while reviewing the videotapes. The change in orientation of the copepods was estimated by drawing a line on an acetate sheet covering the video monitor through the long axis of the copepod in the frame before it began its escape response. The orientation of the copepod in the subsequent frames was measured in a similar manner until the copepod began its high-speed escape jumps. Initial angles of orientation before any response began were measured as the angle between a reference line running through the center of the stimulus rod to the center of the copepod and an orientation line through the long axis of the copepod. We did not differentiate between equal orientation angles on either side of this reference line.

\section{RESULTS}

In order to assess trajectory orientation through body aspect ratio, and to examine the possible impact of size on kinetic measurements, the sizes of 25 adult male and female Acartia tonsa and A. lilljeborgii were quantified in terms of prosome length, maximum prosome width and total body length (excluding furcal setae). Aspect ratios (length:width) used to determine if copepods were moving in a plane perpendicular to the field of view of the camera were 3.28, 3.20, 3.20 and 3.05 for adult female and male $A$. tonsa and adult female and male A. lilljeborgii, respectively. The total body lengths (used in calculation of the Reynolds number) were $1.03 \pm 0.02 \mathrm{~mm}$ and $0.96 \pm 0.05 \mathrm{~mm}$ for adult female and male $A$. tonsa, respectively, and $1.31 \pm$ $0.07 \mathrm{~mm}$ and $1.15 \pm 0.06 \mathrm{~mm}$ for adult female and male A. lilljeborgii, respectively.

In the absence of hydromechanical disturbances, both species of Acartia exhibited characteristic 'hop and sink' behavior. Intermittently, individuals repositioned themselves through short spontaneous jumps involving power strokes of the swimming legs. An example of a digitized speed record for 2 such spontaneous jumps of an $A$. tonsa adult male reveals maximum speeds during these spontaneous jumps of ca. $120 \mathrm{~mm} \mathrm{~s}^{-1}$ (Fig. 2A). Peak accelerations and decelerations during these jumps were both ca. $24 \mathrm{~m} \mathrm{~s}^{-2}$ (Fig. 2B). Such activity was further quantified using 20 spontaneous jumps of adult female $A$. tonsa taken from the $1 \mathrm{~s}$ portions of the high-speed video preceding the stimulus. Of these jumps, 18 were composed of single thrusts of the swimming legs and 2 of double thrusts. These jumps had an average duration of $21 \mathrm{~ms}$ with an average maximum speed of $102 \mathrm{~mm} \mathrm{~s}^{-1}$ and an average maximum acceleration of $27 \mathrm{~m} \mathrm{~s}^{-2}$.

In contrast, the movement kinetics of an escape response to a hydrodynamic stimulus by an adult male Acartia tonsa are of much greater magnitude, and the record of changes in swimming speed (Fig. 3A) and acceleration (Fig. 3B) over time can be correlated with the appendage movements visible on the video images. The brief hydrodynamic stimulus is initiated at $57 \mathrm{~ms}$ (dashed line in Fig. 3). The first movement seen is a rapid turning of the copepod to change its body orientation, begun $3 \mathrm{~ms}$ after the onset of the stimulus; little change in swimming speed is recorded for this behavior. Next, the power strokes of the swimming legs appear as a posteriorly moving fan while the first antennae simultaneously collapse against the prosome. This initial thrust by the swimming legs produces a rapid increase in swimming speed of ca. $500 \mathrm{~mm} \mathrm{~s}^{-1}$ and a maximum acceleration of $210 \mathrm{~m}$ $\mathrm{s}^{-2}$. The subsequent deceleration of $-100 \mathrm{~m} \mathrm{~s}^{-2}$ corresponds to the return of the swimming legs to the pro- 

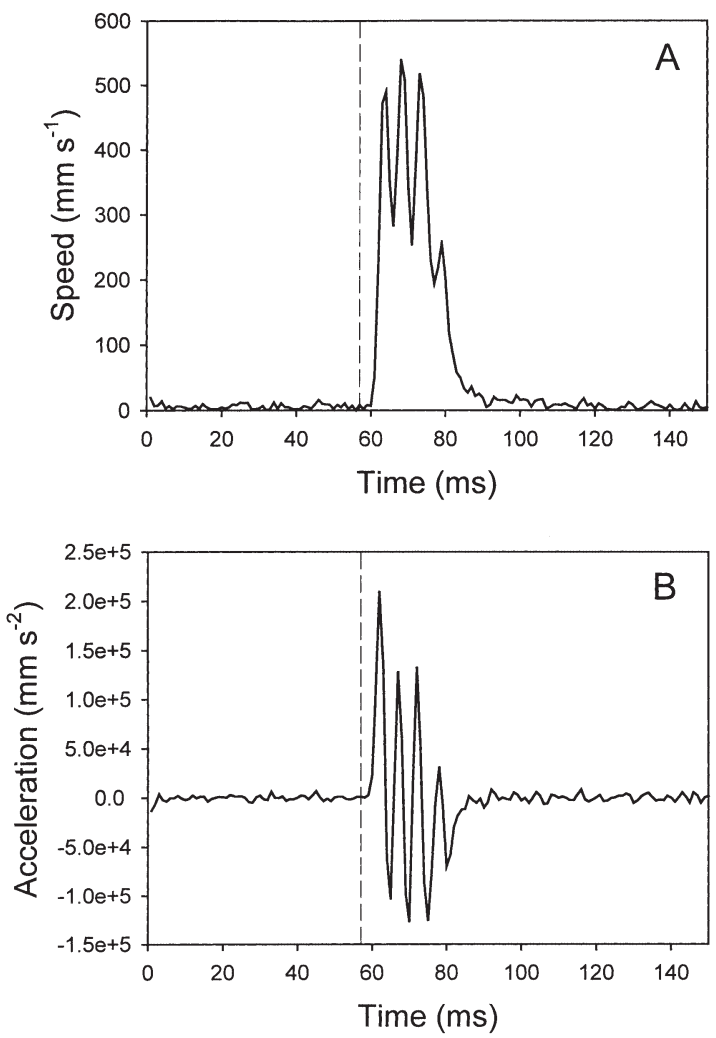

Fig. 3. Acartia tonsa. Example of (A) speed and (B) acceleration records for a representative escape response by an adult male to a defined hydrodynamic disturbance. The stimulus occurred $3 \mathrm{~ms}$ before the initiation of the escape response (dashed line)

moted position (Fig. 3B). This single escape jump was composed of 4 distinct sets of thrusts produced at the extraordinary rate of ca. 200 thrusts $\mathrm{s}^{-1}$. Inertia continues to carry these copepods forward even when they are pulling their swimming legs forward during the recovery stroke. Minimum speed between thrusts of the swimming legs range from ca. 200 to $300 \mathrm{~mm} \mathrm{~s}^{-1}$ in this example. Completion of the escape response is visible in the video images by the return of the swimming legs to the promoted position, redeployment of the first antennae at right angles to the prosome and the return of swimming speed and acceleration to near zero. This entire escape response occurred in ca. $25 \mathrm{~ms}$, less than the duration of a standard video frame at 30 frames s$^{-1}$.

Both the distance of a copepod from the source of the hydrodynamic disturbance and the body's orientation with respect to the disturbance might be expected to have a significant impact on the ability of the copepod to detect a predator. Copepod responses were compared over distance intervals corresponding to multiples of the radius of the stimulus cylinder $(1.5 \mathrm{~mm})$. Only individuals within a few millimeters of the cylin- der responded with an escape jump (Fig. 4). This was expected, since the water deformation rate attenuated rapidly with distance from the cylinder (Eq. 4). Few or no escape responses were observed at distances $>10 \mathrm{~mm}$ from the surface of the cylinder (attenuation of $>99.8 \%$ ). Escapes were triggered with increasing probability in individuals located closer to the cylinder with response rates increasing to ca. $50 \%$ at a distance of $3 \mathrm{~mm}$ (attenuation of $96 \%$ ). Within $1.5 \mathrm{~mm}$ of the cylinder, surface (attenuation of $<88 \%$ ), we observed the highest response rates (50 to $70 \%$ : Fig. 4). While distance from the stimulus had a clear affect on copepod response rate, we did not find evidence of an effect of body orientation on response rate for copepods within $6 \mathrm{~mm}$ of the stimulus surface. The distributions of initial angles of orientation with respect to the stim-
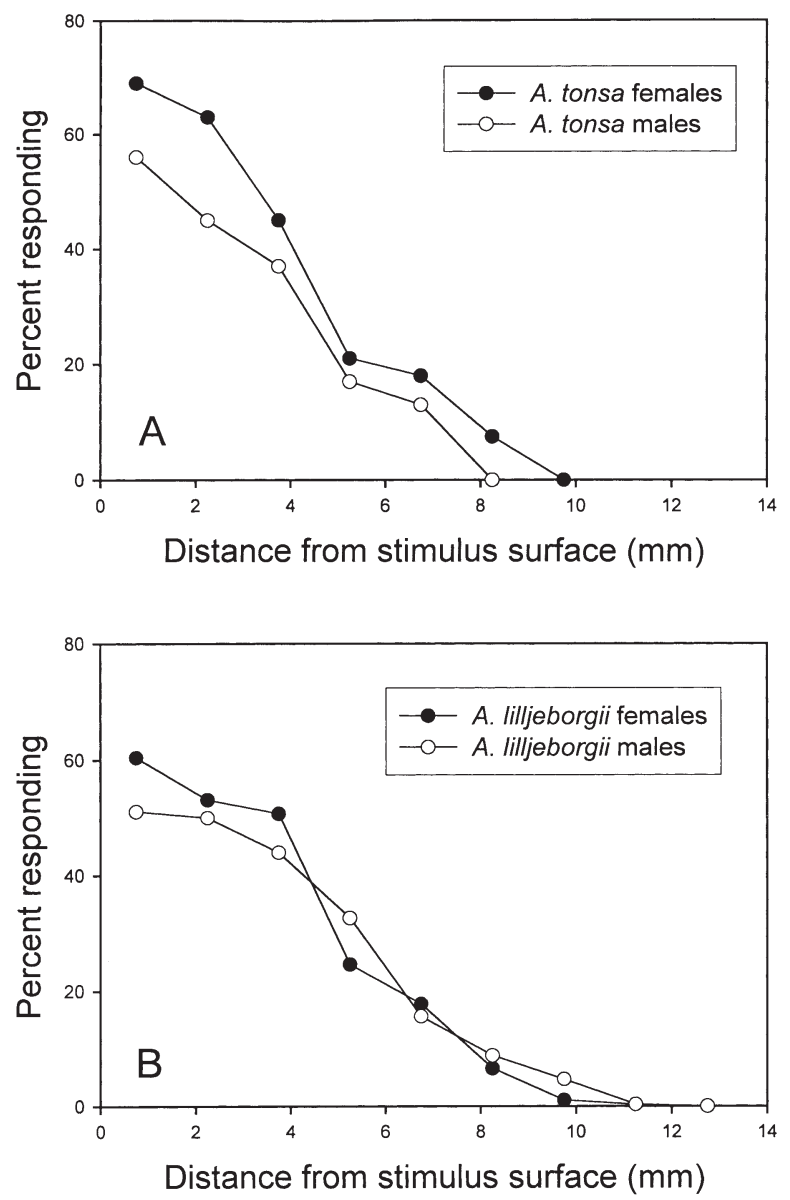

Fig. 4. Acartia tonsa (A) and A. lilljeborgii (B). Proportion of copepods responding to a defined hydrodynamic stimulus at various levels of signal strength. Results from copepods at distance intervals corresponding to multiples of the stimulus radius $(1.5 \mathrm{~mm})$ were pooled to calculate proportion responding. Distance is given to the surface of the cylinder; $1.5 \mathrm{~mm}$ must be added to obtain the distance to the center for hydrodynamic calculations 

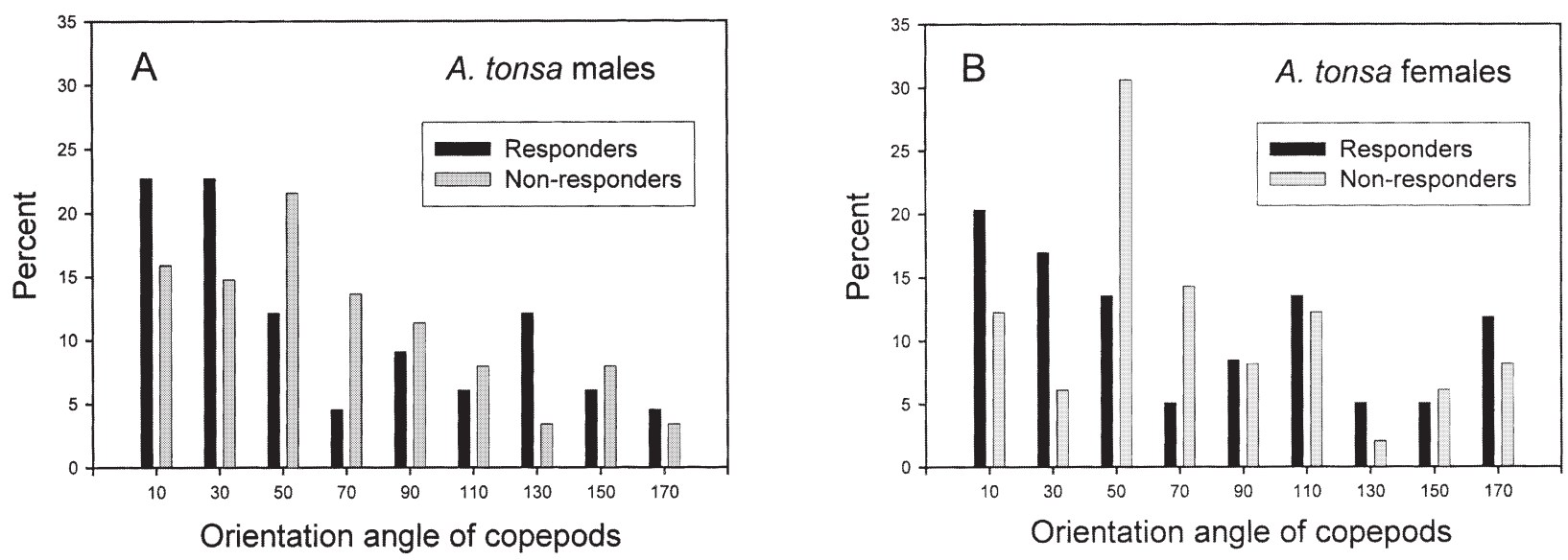

Fig. 5. Acartia tonsa. Orientation of (A) adult males and (B) adult females in the vertical plane with respect to the center of the hydrodynamic stimulus, for copepods within $6 \mathrm{~mm}$ of the stimulus surface. A copepod with its anterior end oriented directly toward the center of the stimulus would have an orientation of $0^{\circ}$, while a copepod perpendicular to the center of the stimulus would have an orientation of $90^{\circ}$ whether directed up or down, and so forth. Results are pooled separately for copepods responding to the hydrodynamic signal with an escape response, and those not responding

ulus for adult male and female Acartia tonsa (Fig. 5) and A. lilljeborgii (data not shown) were similar for copepods responding to the stimulus compared to those not responding. There was no significant difference between the orientation of copepods with respect to the surface of the cylinder for copepods responding to the hydrodynamic stimulus compared to those not responding to the stimulus $(\mathrm{p}=0.437,0.593,0.392$ and 0.450 , Student's $t$-test for $A$. tonsa males, $A$. tonsa females, A. lilljeborgii males and A. lilljeborgii females, respectively).

The faster an animal reacts, the more able it may be in evading a predatory attack. The time between the onset of the computer-controlled hydrodynamic stimulus and the beginning of the behavioral response of the copepods (response latency) ranged from 2 to $9 \mathrm{~ms}$ for all copepods tested. For Acartia tonsa, there was no significant difference between response latencies of adult male and female copepods, with mean latencies of 3.6 and $3.5 \mathrm{~ms}$, respectively (Table 1). However, for A. lilljeborgii, there was a significant difference between latencies of males and females, with mean latencies of $4.7 \mathrm{~ms}$ for males compared to $3.6 \mathrm{~ms}$ for females (Table 2). Comparison between the 2 species reveals no significant difference in latencies for females, but $A$. tonsa males had shorter latencies than A. lilljeborgii males (Table 3).

The escape responses of both species of Acartia typically began with a rapid reorientation of the body before high-speed swimming occurred. Most copepods

Table 1. Acartia tonsa. Summary of escape response variables for adult males and females. Means based on 66 escape jumps for males and 55 jumps for females. Standard error and range are given in parentheses. Probability (p) based on Mann-Whitney rank sum test ( ${ }^{*}$ significant difference: $\alpha=0.05$ ). Prosome lengths are provided for reference

\begin{tabular}{|lccc|}
\hline Variable & Males & Females & $\mathrm{p}$ \\
\hline Prosome length $(\mathrm{mm})$ & $0.78(0.009 ; 0.72-0.86)$ & $0.83(0.004 ; 0.8-0.86)$ & $0.002^{*}$ \\
Response latency $(\mathrm{ms})$ & $3.6(0.2 ; 2-9)$ & $3.5(0.1 ; 2-5)$ & 0.878 \\
Initial turn (degrees) & $82.1(4.9 ; 17-180)$ & $45.9(3.3 ; 0-118)$ & $<0.001^{*}$ \\
Max. turn rate $\left(\right.$ degrees $\left.\mathrm{ms}^{-1}\right)$ & $38.5(2.4 ; 8-108)$ & $26.3(2.0 ; 0-89)$ & $<0.001^{*}$ \\
Jump speed $\left(\mathrm{mm} \mathrm{s}^{-1}\right)$ & $213(7.9 ; 121-403)$ & $188(5.9 ; 135-322)$ & $0.017^{*}$ \\
Max. speed $\left(\mathrm{mm} \mathrm{s}^{-1}\right)$ & $432(13.0 ; 244-656)$ & $372(9.3 ; 236-504)$ & $<0.001^{*}$ \\
Max. acceleration $\left(\mathrm{m} \mathrm{s}^{-2}\right)$ & $163(5.5 ; 88-255)$ & $112(3.2 ; 57-162)$ & $<0.001^{*}$ \\
No. of thrusts & $3.1(0.2 ; 2-7)$ & $3.3(0.2 ; 1-9)$ & 0.518 \\
Min. speed between thrusts $\left(\mathrm{mm} \mathrm{s}^{-1}\right)$ & $166(6.4 ; 63-368)$ & $133(4.3 ; 62-251)$ & $<0.001^{*}$ \\
Time between thrusts $(\mathrm{ms})$ & $6.1(0.1 ; 2-13)$ & $6.6(0.2 ; 2-10)$ & $<0.001^{*}$ \\
Jump duration (ms) & $19.3(0.9 ; 9-44)$ & $24.1(1.0 ; 16-51)$ & $<0.001^{*}$ \\
Distance jumped (mm) & $4.2(0.3 ; 1.6-9.9)$ & $4.6(2.3-12.2)$ & 0.070 \\
\hline
\end{tabular}


Table 2. Acartia lilljeborgii. Summary of escape response parameters for adult males and females. Means based on 68 escape jumps for males and 56 jumps for females. Standard error and range are given in parentheses. Probability (p) based on MannWhitney rank sum test $\left({ }^{*}\right.$ significant difference: $\left.\alpha=0.05\right)$. Prosome lengths are provided for reference

\begin{tabular}{|lccc|}
\hline Variable & Males & Females & $\mathrm{p}$ \\
\hline Prosome length $(\mathrm{mm})$ & $0.92(0.006 ; 0.88-0.96)$ & $1.03(0.012 ; 0.92-1.08)$ & $<0.001^{*}$ \\
Response latency $(\mathrm{ms})$ & $4.7(0.2 ; 2-9)$ & $3.6(0.1 ; 2-6)$ & $<0.001^{*}$ \\
Initial turn (degrees) & $46.4(3.7 ; 0-136)$ & $47.9(3.5 ; 0-163)$ & 0.496 \\
Max. turn rate (degrees $\left.\mathrm{ms}^{-1}\right)$ & $27.1(2.4 ; 0-98)$ & $27.8(1.9 ; 0-90)$ & 0.17 \\
Jump speed $\left(\mathrm{mm} \mathrm{s}^{-1}\right)$ & $273(12.8 ; 150-573)$ & $232(7.6 ; 130-388)$ & $0.030^{*}$ \\
Max. speed (mm s$\left.{ }^{-1}\right)$ & $607(13.6 ; 393-840)$ & $486(11.7 ; 206-612)$ & $<0.001^{*}$ \\
Max. acceleration $\left(\mathrm{m} \mathrm{s}^{-2}\right)$ & $220(5.9 ; 110-319)$ & $138(3.6 ; 87-187)$ & $<0.001^{*}$ \\
No. of thrusts & $2.6(0.2 ; 1-7)$ & $2.5(0.1 ; 1-5)$ & 0.867 \\
Min. speed between thrusts $\left(\mathrm{mm} \mathrm{s}^{-1}\right)$ & $217(9.7 ; 55-465)$ & $198(8.1 ; 58-342)$ & 0.278 \\
Time between thrusts $(\mathrm{ms})$ & $7.7(0.2 ; 3-13)$ & $7.8(0.2 ; 3-12)$ & 0.376 \\
Jump duration $(\mathrm{ms})$ & $23.8(1.5 ; 10-67)$ & $6.4(0.3 ; 2.8-12.3)$ & $<.001^{*}$ \\
Distance jumped $(\mathrm{mm})$ & $6.0(0.3 ; 2.3-13.7)$ & & 0.313 \\
\end{tabular}

(>98\% of responses) appeared to turn in place for 1 or $2 \mathrm{~ms}$ (mean $1.6 \mathrm{~ms}$ ), with a resulting reorientation ranging from $<10$ to a maximum of $180^{\circ}$. In $A$. tonsa, adult males had significantly larger initial turns and significantly faster maximum turning rates than adult females (Table 1). For A. lilljeborgii, there was no significant difference between adult males and females for either the extent of the initial turn or the maximum rate of turn (Table 2). Comparison between the 2 species show that there were no significant differences in initial turning behavior for adult female copepods, but male A. tonsa exhibited larger and more rapid initial turns than male A. lilljeborgii (Table 3). To assess the impact of these turns on the efficacy of the escape response, the final locations where the copepods would have ended their escape responses were calculated with and without the initial turn, based on the distance each copepod jumped (Table 3 ) and assuming a linear escape path. On average, the copepods ended up $2.3 \mathrm{~mm}$ further away from the source of the disturbance for $A$. tonsa and $2.7 \mathrm{~mm}$ further away for $A$. lilljeborgii than if they had not turned.

Once reorientation occurs, the effectiveness of an escape depends on how fast, how far and in what direction the animal travels. The initial turn was the major factor determining the direction of the highspeed escape trajectories; usually only slight deviations from the initial direction of escape occurred. The overall distribution of directions of travel in the vertical plane during escape responses for Acartia tonsa males (Fig. 6A) and A. tonsa females (Fig. 6B) were upward or lateral. When swimming speeds are averaged over the entire escape response (defined as speed records exceeding a 'noise' threshold of $25 \mathrm{~mm} \mathrm{~s}^{-1}$ ), they range from about 120 to $>570 \mathrm{~mm} \mathrm{~s}^{-1}$. Maximum speeds during these escape responses averaged $372 \mathrm{~mm} \mathrm{~s}^{-1}$, and could reach $>800 \mathrm{~mm} \mathrm{~s}^{-1}$. Maximum accelerations averaged $112 \mathrm{~m} \mathrm{~s}^{-2}$ and could exceed $300 \mathrm{~m} \mathrm{~s}^{-2}$.

Table 3. Acartia tonsa (AT) and A. lilljeborgii (AL). Comparison of size and mean escape response variables between species for adult males and adult females. Probability (p) based on Mann-Whitney rank sum test ( ${ }^{*}$ significant difference: $\alpha=0.05$ )

\begin{tabular}{|c|c|c|c|c|c|c|}
\hline \multirow[t]{2}{*}{ Variable } & \multicolumn{3}{|c|}{ Males } & \multicolumn{3}{|c|}{ Females } \\
\hline & $\mathrm{AT}$ & $\mathrm{AL}$ & $\mathrm{p}$ & $\mathrm{AT}$ & $\mathrm{AL}$ & $\mathrm{p}$ \\
\hline Prosome length (mm) & 0.78 & 0.92 & $<0.001^{*}$ & 0.83 & 1.03 & $<0.001^{*}$ \\
\hline Response latency (ms) & 3.6 & 4.7 & $<0.001^{*}$ & 3.5 & 3.6 & 0.608 \\
\hline Initial turn (degrees) & 82.1 & 46.4 & $<0.001^{*}$ & 45.9 & 47.9 & 0.534 \\
\hline Max. turn rate (degrees $\mathrm{ms}^{-1}$ ) & 38.5 & 27.1 & $<0.001^{*}$ & 26.3 & 27.8 & 0.263 \\
\hline Jump speed $\left(\mathrm{mm} \mathrm{s}^{-1}\right)$ & 213 & 273 & $<0.001^{*}$ & 188 & 232 & $<0.001^{*}$ \\
\hline Max. speed $\left(\mathrm{mm} \mathrm{s}^{-1}\right)$ & 432 & 607 & $<0.001^{*}$ & 372 & 486 & $<0.001^{*}$ \\
\hline Max. acceleration $\left(\mathrm{m} \mathrm{s}^{-2}\right)$ & 163 & 220 & $<0.001^{*}$ & 112 & 138 & $<0.001^{*}$ \\
\hline No. of thrusts & 3.1 & 2.6 & 0.108 & 3.3 & 2.5 & $0.047^{*}$ \\
\hline Min. speed between thrusts $\left(\mathrm{mm} \mathrm{s}^{-1}\right.$ ) & 166 & 217 & $<0.001^{*}$ & 133 & 198 & $<0.001^{*}$ \\
\hline Time between thrusts (ms) & 6.1 & 7.7 & $<0.001^{*}$ & 6.6 & 7.8 & $<0.001^{*}$ \\
\hline Jump duration (ms) & 19.3 & 23.8 & $0.004^{*}$ & 24.1 & 27.7 & $0.003^{*}$ \\
\hline Distance jumped (mm) & 4.2 & 6.0 & $<0.001^{*}$ & 4.6 & 6.4 & $<0.001^{*}$ \\
\hline
\end{tabular}



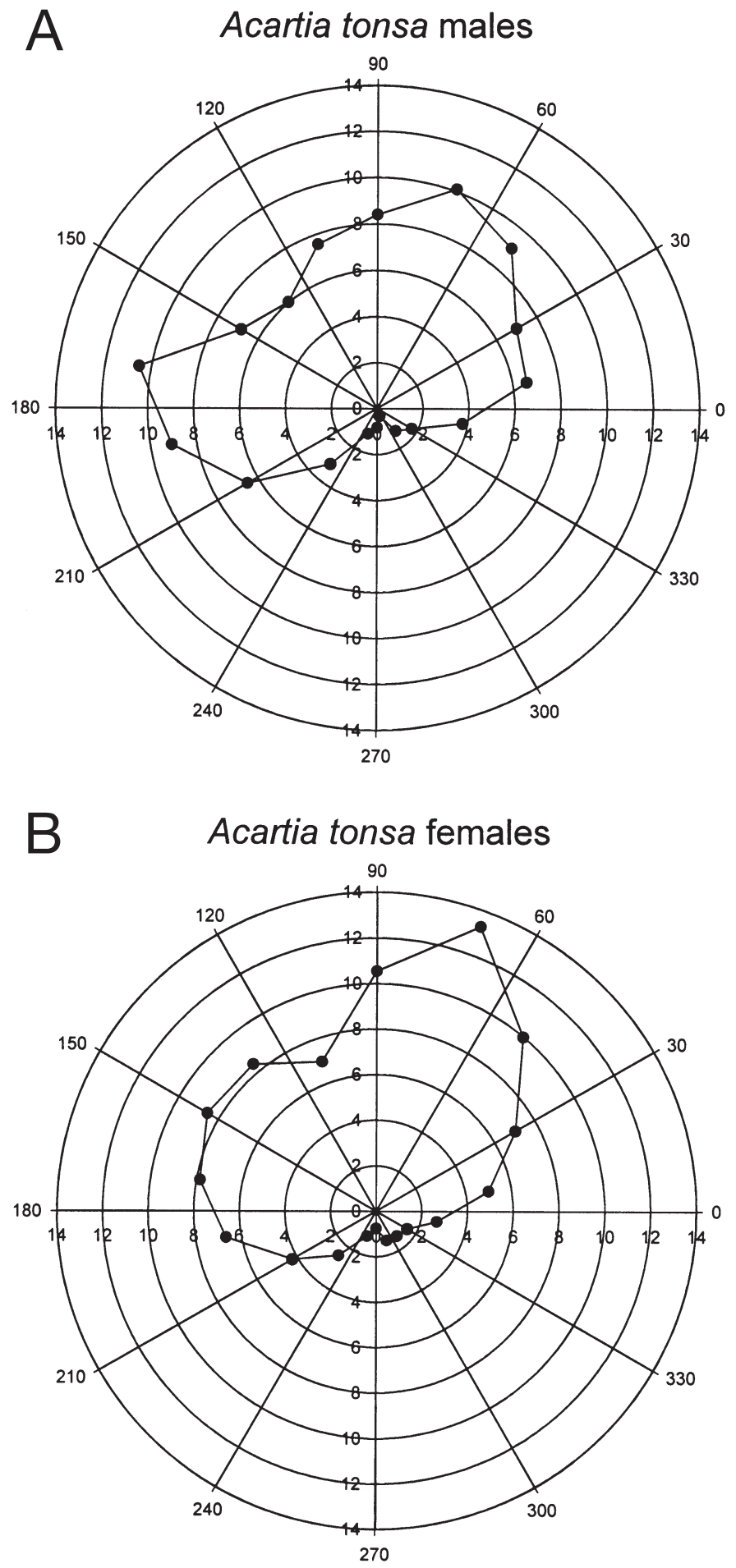

Fig. 6. Acartia tonsa. Polar plots of direction of travel in the vertical plane for (A) adult males and (B) adult females during high-speed escape responses. Plots indicate the percent of total escape-path segments falling into each of 18 directional categories of $20^{\circ}(\bullet)$. The direction of the stimulus corresponds to $0^{\circ}$; $90^{\circ}$ and $270^{\circ}$ correspond to vertically upward- and downwarddirected movements, respectively
A. tonsa males have significantly faster average speeds than females over the entire escape response, significantly higher maximum speeds, and significantly greater maximum accelerations (Table 1). Histograms comparing the distributions of maximum speeds for all escape jumps of adult male and female $A$. tonsa are shown in Fig. 7. Males exhibited a broader bimodal distribution of maximum speeds than females. A. lilljeborgii males also had significantly faster average speeds than females, significantly higher maximum speeds, and significantly greater accelerations (Table 2). Comparison between the 2 species revealed that both male and female A. lilljeborgii (the larger species) had significantly faster swimming speeds and accelerations during escape jumps than A. tonsa (Table 3). Regression analysis was performed to examine whether there was any relationship between distance from the stimulus (corresponding to signal strength) and the speed or acceleration of the copepods' escape responses. No significant relationships were found (data not shown).

Each escape response to the hydrodynamic stimulus consisted of a minimum of 1 , and up to 9 successive thrusts of the swimming legs in rapid succession. There was no difference between adult males and females of either copepod species in the number of separate thrusts of the swimming legs during the escape response. For Acartia tonsa, however, adult males had significantly shorter average intervals between swimming leg thrusts than did adult females, and significantly faster minimum speeds between swimming leg thrusts, i.e. their inertial movement during recovery strokes (Table 1 ). There was no significant difference between male and female A. lilljeborgii in these parameters, however (Table 2). Comparisons between the 2 species showed that $A$. lilljeborgii had more inertia between thrusts of the swimming legs, exhibiting significantly greater speeds than A. tonsa during the recovery strokes for both males and females (Table 3).

The total duration of a single escape jump, defined as a series of successive swimming leg thrusts not interrupted by even a short period of inactivity, ranged from 9 to $67 \mathrm{~ms}$. Most of these escape jumps would occur in less than the duration of a single standard video frame (ca. $33 \mathrm{~ms}$ for NTSC video; $40 \mathrm{~ms}$ for PAL video). For both species of Acartia studied, adult males had jumps of significantly shorter duration than adult female copepods (Tables $1 \& 2$ ). When jump durations are compared between the 2 species, the escape jumps of A. lilljeborgii were significantly longer than those of A. tonsa for both males and females (Table 3). However, there was no significant difference between males and females of either species studied in the average distance jumped (Tables $1 \& 2$ ), but escape jumps 
of $>6 \mathrm{~mm}$ were significantly longer for A. lilljeborgii compared to those of $A$. tonsa, which averaged $>4 \mathrm{~mm}$ (Table 3). Based on prosome lengths, this corresponds to an escape jump of ca. 5 body lengths for $A$. tonsa and ca. 6 body lengths for A. lilljeborgii.

\section{DISCUSSION}

Calanoid copepods are consumed by a wide range of predators in the marine environment, and their fast, vigorous escape behaviors represent important adaptations for avoiding predation and may play an important role in selective feeding of planktivores (Drenner et al. 1978). Several previous studies have quantified the swimming speeds of copepod escape responses stimulated both by mechanical and photic stimuli. Typically these studies have made use of standard video with a maximum temporal resolution of 50 (PAL) or 60 (NTSC) scans s ${ }^{-1}$ (2 scans of alternate lines comprise 1 video frame). Escape speeds based on these measures have typically calculated speeds corresponding to $<100$ body lengths $\mathrm{s}^{-1}$ (e.g. Haury et al. 1980, Buskey et al. 1986, Yen 1988, Suchman 2000). Using highspeed cinematography (250 frames s${ }^{-1}$ ), Strickler (1975) measured maximum escape speeds of ca. $800 \mathrm{~mm} \mathrm{~s}^{-1}$ for an unidentified freshwater species of Cyclops of $1.5 \mathrm{~mm}$ length. In this study, using a higher temporal resolution (1000 frames $\mathrm{s}^{-1}$ ) we have measured maximum speeds in a similar range; up to $656 \mathrm{~mm} \mathrm{~s}^{-1}$ for Acartia tonsa ( 0.8 $\mathrm{mm}$ prosome length) and $840 \mathrm{~mm}$ $\mathrm{s}^{-1}$ for $A$. lilljeborgii ( 1 $\mathrm{mm}$ prosome length). The higher temporal resolution results in much higher measures of acceleration than previously reported from high-speed cinematography, however. Strickler (1975) reported maximum accelerations of $12 \mathrm{~m} \mathrm{~s}^{-2}$ for Cyclops sp., whereas we have calculated accelerations up to $255 \mathrm{~m} \mathrm{~s}^{-2}$ for $A$. tonsa and $319 \mathrm{~m} \mathrm{~s}^{-2}$ for $A$. lilljeborgii. We have also measured very rapid initial turning in the escape behavior of Acartia, with maximum initial turning rates of $108^{\circ} \mathrm{ms}^{-1}$ for $A$. tonsa and $98^{\circ}$ $\mathrm{ms}^{-1}$ for $A$. lilljeborgii. These kinetic parameters are quite impressive for a small aquatic animal, and compare favorably to the well-known study of the jump of a $1.5 \mathrm{~mm}$ flea, which has a similar maximum velocity of ca. $1 \mathrm{~m} \mathrm{~s}^{-1}$, although the flea has a clear advantage in air with an impressive acceleration of $1330 \mathrm{~m} \mathrm{~s}^{-2}$ (Bennet-Clark \& Lucey 1967). Thus our study confirms the basic results of Strickler (1975) on swimming speed, extends them to small calanoid copepods, and raises the measures for peak acceleration by over an order of magnitude.

Copepods are arguably the most abundant form of metazoan life on earth, and have evolved into more than 11500 species (Humes 1994). It has been sug-
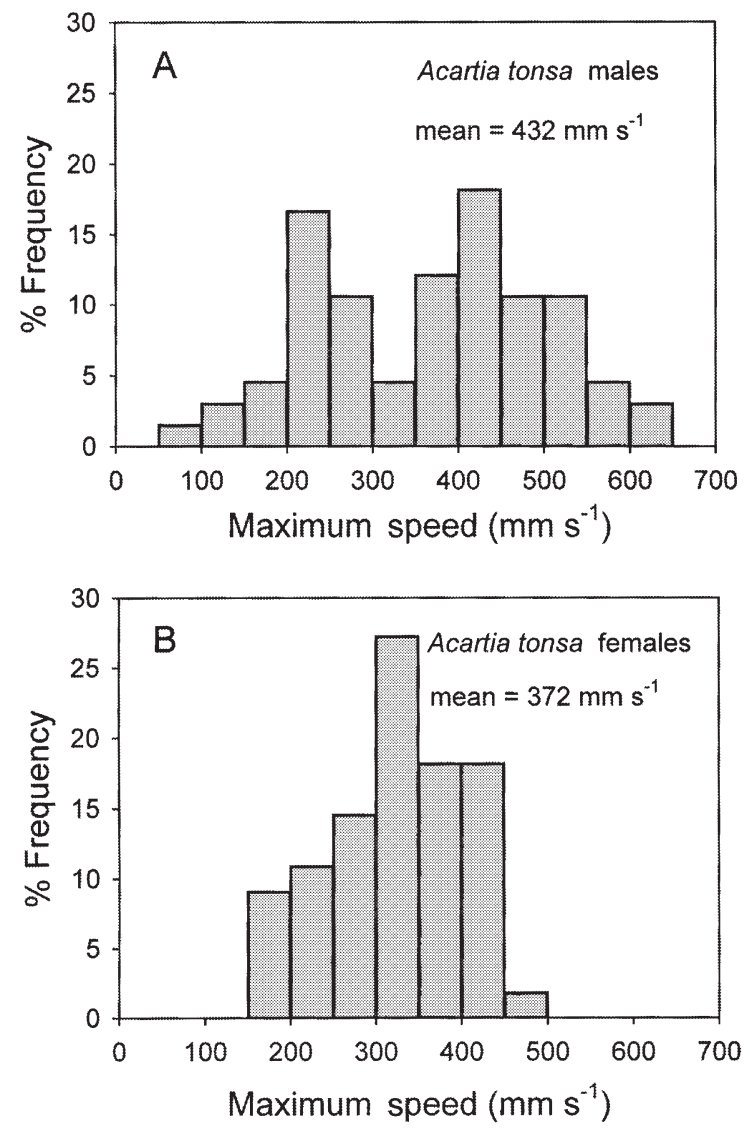

Fig. 7. Acartia tonsa. Distribution of maximum speeds recorded during each escape response for (A) adult males and

(B) adult females

gested that one reason for their extraordinary success lies in the fact that their behaviors allow them to take advantage of both viscous and inertial forces in the planktonic realm (Naganuma 1996, Yen 2000). Feeding by most calanoid copepods takes place in the viscous realm of low Reynolds numbers $(<1)$, which creates a predictable laminar feeding current (Koehl \& Strickler 1981, Strickler 1982) and allows efficient capture of food particles. For routine swimming behavior, the Reynolds numbers of swimming copepods fall mainly in the range between 1 for a $1 \mathrm{~mm}$ copepod swimming at ca. $1 \mathrm{~mm} \mathrm{~s}^{-1}$ to about 50 for a 3 to $4 \mathrm{~mm}$ copepod swimming at ca. $15 \mathrm{~mm} \mathrm{~s}^{-1}$ (summarized in Mauchline 1998). Escape behaviors with speeds approaching $1 \mathrm{~m} \mathrm{~s}^{-1}$ take place at much higher Reynolds numbers in quasi-turbulent flow (Yen \& Strickler 1996). During escape jumps copepods become highly streamlined with all appendages folded tightly against the body. During each sequential set of thrusts of the swimming legs, Acartia spp. can reach maximum speeds of ca. $800 \mathrm{~mm} \mathrm{~s}^{-1}$, which corresponds to a Reynolds number of ca. 920 for a $1.15 \mathrm{~mm}$ adult male 
A. lilljeborgii. Minimum speed between successive thrusts of the swimming legs can be as high as $465 \mathrm{~mm}$ $\mathrm{s}^{-1}$, which corresponds to a Reynolds number of ca. 535. This rapid minimum speed during the recovery segments of a multi-stroke escape response clearly indicates the inertial nature of their motion; they continue to glide forward during recovery strokes.

Behavioral responses to hydrodynamic signals have been previously studied in Acartia tonsa primarily by using siphon flow or other devices to generate water movements (Fields \& Yen 1997b, Kiørboe et al. 1999). In planktonic organisms, it is usually accepted that the primary effective stimulus is water deformation, since the whole animal is carried along by bulk flow which it lacks the sensory organs to detect (Haury et al. 1980, Yen et al. 1992, Kiørboe \& Visser 1999). Fields \& Yen (1997b) reported shear values of $1.5 \mathrm{~s}^{-1}$ producing escapes in $50 \%$ of adult $A$. tonsa tested (recomputed to be $0.38 \mathrm{~s}^{-1}$ by Kiørboe et al. 1999). Kiørboe et al. (1999) reported a range of 0.2 to $0.4 \mathrm{~s}^{-1}$ with an average threshold deformation rate of $0.34 \mathrm{~s}^{-1}$ for the same species. Our computed values (Eq. 4) at a $50 \%$ response level ranged from 2.5 to $12 \mathrm{~s}^{-1}$ for our 4 different Acartia spp. groupings (Fig. 4). However, we found significant responsiveness down to deformation rates of $0.4 \mathrm{~s}^{-1}$. Along an antenna of $0.8 \mathrm{~mm}$ length, this would produce flow-speed differentials of ca. $0.03 \mathrm{~cm}$ $\mathrm{s}^{-1}$. The copepods are highly sensitive; they responded to net relative water movements of as little as $130 \mathrm{~nm}$ in a bulk flow of $0.8 \mu \mathrm{m}$.

Our experiments broaden the range of stimulus temporal characteristics studied. Values for a threshold derived from siphon experiments in which waterdeformation rates build up relatively slowly as the copepod approaches the mouth of the siphon are close to those we have found using a stimulus with a much more rapid build-up of deformation rate (milliseconds). This raises the issue of why copepods, in contrast to other crustaceans, are sensitive over such a wide temporal range of hydrodynamic disturbances. It is interesting in this respect that copepod predators, which include such diverse organisms as whales, fishes, cnidarians, chaetognaths and predatory copepods, are likely to generate hydrodynamic signals that vary considerably over spatial and temporal scales. A critical deformation rate, regardless of how it is achieved, may be a key stimulus activating the escape mechanism.

Behavioral thresholds for free-swimming Acartia spp. are higher than those measured using the same stimulus in tethered larger calanoid copepods $\left(0.003 \mathrm{~cm} \mathrm{~s}^{-1}\right.$ in Undinula vulgaris: Lenz \& Hartline 1999; $0.002 \mathrm{~cm} \mathrm{~s}^{-1}$ in Labidocera madurae: Hartline et al. 1996). They are also well above those measured physiologically for sensory neurons in other species $\left(0.002 \mathrm{~cm} \mathrm{~s}^{-1}\right.$ in L. madurae: Yen et al. $1992 ; 0.003 \mathrm{~cm}$ $\mathrm{s}^{-1}$ in Pleuromamma xiphias and Euchaeta rimana: Lenz \& Yen 1993). This supports the conclusions of Kiørboe et al. (1999) that in Acartia spp. a substantial summation of neural excitation may be needed to elicit an escape response.

Variability in reactivity was quite large in these experiments, as it has proven to be in other experiments on Acartia spp. and other copepods using siphon tube stimuli (Fields \& Yen 1996, 1997b, Viitasalo et al. 1998, Kiørboe et al. 1999). Even stimuli $>10$ times threshold elicited escape in only $60 \%$ of our individuals. Under the experimental conditions this could not be explained on the basis of external factors such as orientation to the stimulus (Fig. 5). It seems likely that there is a significant variability in behavioral state that strongly affects escape reactivity.

Differential predation rates on male and female copepods have been previously demonstrated. Differences in size or visual conspicuousness may explain some of the variation (Drenner et al. 1978, Drenner \& McComas 1980, Svensson 1992). We found significant differences between adult male and female copepods of the same species for behavioral parameters describing the kinetics of their escape responses (Tables 1 \& 2). Males of both species studied had shorter duration jumps of higher speed and greater maximum acceleration than females. Females appear to be slightly more sensitive to hydrodynamic stimuli than males (Fig. 4), and this may help to compensate for their slightly weaker escape responses. Comparing the 2 species of Acartia, the larger species, A. lilljeborgii, generally has a more vigorous escape response than the slightly smaller A. tonsa (Table 3). As escape responses of more copepods species are subjected to detailed, high temporal-resolution study, it will become possible to determine if larger copepods generally have faster escape responses that help compensate for their increased conspicuousness to visual predators.

The typical swimming pattern of Acartia spp. has been described as short jumps followed by motionless slow sinking, a 'hop and sink' swimming pattern (Gauld 1966, Tiselius \& Jonsson 1990). These typical spontaneous hops (Fig. 2) are clearly quite different from the high-speed escape responses stimulated by hydrodynamic disturbances in this study (Fig. 3, Tables 1 \& 2). While spontaneous motion patterns such as hop and sink behavior may provide important visual and hydrodynamic cues for planktivores (Zaret 1980, Buskey et al. 1993), it seems unlikely that predators such as fishes could visually resolve details of the kinetics of an escape response, since their critical flicker-fusion frequencies under natural underwater light intensities (40 to $60 \mathrm{~Hz}$ : Douglas \& Hawryshyn 1990) would not allow the resolution of swimming leg thrusts separated by 6 to $8 \mathrm{~ms}$. These rapid thrusts at 
ca. $150 \mathrm{~Hz}$ could produce strong hydrodynamic signals to non- visual predators such as chaetognaths (Feigenbaum \& Reeve 1977), predatory copepods (Yen \& Strickler 1996) and other non-visual predators that make use of hydrodynamic signals, however. For scyphomedusan predators, the overall speed of the escape response may be the most important factor affecting predator success (Costello \& Colin 1995).

The time delay between the stimulus (threat) and the behavioral response is a critical component of an organism's escape response. Studies of behavioral responses to hydrodynamic signals using siphon flow or natural predators (Yen \& Fields 1992, Fields \& Yen 1997b, Kiørboe et al. 1999) do not allow for determination of response latencies since the onset time of the stimulus is unknown. Short latencies $(<1 \mathrm{~ms})$ to the first preparatory movement have been measured in calanoid copepods possessing myelinated nervous systems (Davis et al. 1999, Lenz \& Hartline 1999, Lenz et al. 2000). We recorded minimum response delays of $2 \mathrm{~ms}$ to first movement for both species of Acartia examined, neither of which are thought to possess myelinated nerves. Power strokes by the swimming legs, as determined by the start of rapid acceleration, were usually delayed by an additional 1 to $2 \mathrm{~ms}$, since most individuals turned prior to the forward thrust. While not as fast to react as the larger, myelinated Undinula vulgaris, Acartia spp., perhaps owing to their smaller size and shorter distances between mechanosensors and swimming leg muscles, achieve exceedingly fast response times.

The potential significance of turning movements in copepod escape has not been generally emphasized and needs to receive more attention. The data presented by Haury et al. (1980) imply that turns are made by Calanus finmarchicus copepodids, based on trajectory analysis. Fields \& Yen (1997a) found only a limited ability of Acartia hudsonica nauplii to alter direction once entrained in the flow-field of Euchaeta rimana (means of $\pm 10^{\circ}$ ). Rapid and large turns of up to $180^{\circ}$ can be characteristic of escape reactions in 2 Acartia species (Tables $1 \& 2$ ). These turns can result in individuals moving further away from the source of a perturbation, but they also add to the delay preceding periopod power strokes. The interplay of these costbenefit factors is of potential ecological significance. Turning implies that, prior to the activation of the periopod power strokes, processing in the central nervous system is activating different muscles to produce reorientation of the copepod. It is consistent with the 'preparatory' movement of tethered animals (Lenz \& Hartline 1999) being related to re-orientation. Thus, the sensorimotor system for the escape is not only fast but also more complex than previously thought (Lowe 1935, Park 1966, Lenz et al. 2000).
Several factors may determine the effectiveness of copepod escape responses, including sensitivity to hydrodynamic stimuli, response latencies and kinetic characteristics of the escape jump itself (i.e. speed, acceleration, direction, distance jumped). Most recent studies have emphasized the quantification of hydrodynamic sensitivity thresholds (Viitasalo et al. 1998, Kiørboe \& Visser 1999) and response latencies (Lenz \& Hartline 1999, Lenz et al. 2000) to understand the role of escape behavior in predator-prey interactions. As more data become available from a wider range of species on the detailed kinetics of escape responses of free-swimming copepods, an improved understanding of the role of escape behavior in structuring planktonic communities will be achieved.

Acknowledgements. This research was supported by the National Science Foundation through Grants OCE 9910608 to E.J.B. and OCE 9906223 to P.H.L. and D.K.H. Cammie Hyatt and Becky Waggett assisted with sorting of copepods for experiments and data analysis. We are grateful to H. Akaka, D. Gassie, B. Jones and R. Sanborn for development of the hardware and software used for the hydrodynamic stimulus. We thank Dr. Bo Qiu for assistance with hydrodynamics of the stimulus cylinder. This is University of Texas Marine Science Institute Contribution Number 1201.

\section{LITERATURE CITED}

Angel MV (1985) Vertical migration in the oceanic realm: possible causes and probable effects. Contrib Mar Sci 27 (Suppl):45-70

Batchelor, GK (1967) An introduction to fluid dynamics. Cambridge University Press, Cambridge

Bennet-Clark HC, Lucey ECA (1967) The jump of the flea: a study of the energetics and a model of the mechanism. J Exp Biol 47:59-76

Buskey EJ (1994) Factors affecting feeding selectivity of visual predators on the copepod Acartia tonsa: locomotion, visibility and escape responses. Hydrobiologia 292/293: 447-453

Buskey EJ, Mann CG, Swift E (1986) The shadow response of the estuarine copepod Acartia tonsa (Dana). J Exp Biol Ecol 103:65-75

Buskey EJ, Coulter C, Strom S (1993) Locomotory patterns of microzooplankton: potential effects on food selectivity of larval fish. Bull Mar Sci 53:29-43

Costello JH, Colin SP (1995) Flow and feeding by swimming scyphomedusae. Mar Biol 124:399-406

Davis AD, Weatherby TM, Hartline DK, Lenz PH (1999) Myelin-like sheaths in copepod axons. Nature 398:571

Douglas RH, Hawryshyn CW (1990) Behavioural studies of fish vision: an analysis of visual capabilities. In: Douglas RH, Djamgoz MBA (eds) The visual system of fish. Chapman \& Hall, London, p 373-418

Drenner RW, McComas SR (1980) The roles of zooplankton escape ability and fish size selectivity in the selective feeding and impact of planktivorous fish. In: Kerfoot WC (ed) Evolution and ecology of zooplankton communities. University Press of New England, Hanover, NH, p 587-593

Drenner RW, Strickler JR, O'Brien WJ (1978) Capture proba- 
bility: the role of zooplankton escape in the selective feeding of planktivorous fish. J Fish Res Bd Can 35:1370-1373

Feigenbaum D, Reeve MR (1977) Prey detection in the Chaetognatha: response to a vibrating probe and experimental determination of attack distance in large aquaria. Limnol Oceanogr 22:1052-1058

Fields DM, Yen J (1996) The escape behavior of Pleuromamma xiphias in response to a quantifiable fluid mechanical disturbance. Mar Freshw Behav Physiol 27: 323-340

Fields DM, Yen J (1997a) Implications of the feeding current structure of Euchaeta rimana, a carnivorous pelagic copepod, on the spatial orientation of their prey. J Plankton Res 19:79-95

Fields DM, Yen J (1997b) The escape behavior of marine copepods in response to a quantifiable fluid mechanical disturbance. J Plankton Res 19:1289-1304

Forward RB Jr (1976) Light and diurnal vertical migration: photobehavior and photophysiology of plankton. In: Smith KC (ed) Photochemical and photobiological reviews, Vol 1. Plenum Publishing, New York, p 157-209

Gassie DV, Lenz PH, Yen J, Hartline DK (1993) Mechanoreception in zooplankton first antennae: electrophysiological techniques. Bull Mar Sci 53:96-105

Gauld DT (1966) The swimming and feeding of planktonic copepods. In: Barnes $\mathrm{H}$ (ed) Some contemporary studies in marine science. Allen \& Irwin, London, p 313-334

Greze VN (1963) The determination of transparency among planktonic organisms and its protective significance. Dolk Akad Nauk SSSR 151:435-438

Hartline DK, Lenz PH, Herren CM (1996) Physiological and behavioral studies of escape responses in calanoid copepods. Mar Freshw Behav Physiol 27:199-212

Hartline DK, Buskey EJ, Lenz PH (1999) Rapid jumps and bioluminescence elicited by controlled hydrodynamic stimuli in a mesopelagic copepod, Pleuromamma xiphias. Biol Bull 197:132-143

Haury LR, Kenyon DE, Brooks JR (1980) Experimental evaluation of the avoidance reaction of Calanus finmarchicus. J Plankton Res 2:187-202

Herring PJ (1988) Copepod luminescence. Hydrobiologia 167/168:183-195

Humes AG (1994) How many copepods? Hydrobiologia 292/293:1-7

Kerfoot WC (1980) Commentary: transparency, body size and prey conspicuousness. In: Kerfoot WC (ed) Evolution and ecology of zooplankton communities. University Press of New England, Hanover, NH, p 609-617

Kiørboe T, Visser AW (1999) Predator and prey perception in copepods due to hydromechanical signals. Mar Ecol Prog Ser 179:81-95

Kiørboe T, Saiz E, Visser A (1999) Hydrodynamic signal perception in the copepod Acartia tonsa. Mar Ecol Prog Ser 179:97-111

Koehl MAR, Strickler JR (1981) Copepod feeding currents: food capture at low Reynolds number. Limnol Oceanogr 26:1062-1073

Kundu PK (1990) Fluid mechanics. Academic Press, San Diego, CA

Lenz PH, Hartline DK (1999) Reaction times and force production during escape behavior of a calanoid copepod Undinula vulgaris. Mar Biol 133:249-258

Lenz PH, Yen J (1993) Distal setal mechanoreceptors of the first antennae of marine copepods. Bull Mar Sci 53:170-179

Editorial responsibility: Thomas Kiørboe (Contributing Editor), Charlottenlund, Denmark
Lenz PH, Hartline DK, Davis A (2000) The need for speed. I. Fast reactions and myelinated axons in copepods. J Comp Physiol A Sens Neural Behav Physiol 186:337-345

Lowe E (1935) On the anatomy of a marine copepod, Calanus finmarchicus (Gunnerus). Trans R Soc Edinb 58:561-603

Mauchline J (1998) The biology of calanoid copepods. Adv Mar Biol 33:1-710

Naganuma T (1996) Calanoid copepods: linking lower-higher trophic levels by linking lower-higher Reynolds numbers. Mar Ecol Prog Ser 136:311-313

Park TS (1966) The biology of a calanoid copepod Epilabidocera amphitrites McMarrich. Cellule 66:129-251

Russell FS (1927) The vertical distribution of plankton in the sea. Biol Rev 2:213-261

Singarajah KV (1969) Escape reactions of zooplankton: avoidance of a pursuing siphon tube. J Exp Mar Biol Ecol 3: $171-178$

Strickler JR (1975) Swimming of planktonic Cyclops species (Copepoda, Crustacea): pattern, movements and their control. In: Wu TWT, Brokaw CJ, Brennen C (eds) Swimming and flying in nature. Plenum Press, Princeton, NJ, p 599-616

Strickler JR (1982) Calanoid copepods, feeding currents, and the role of gravity. Science 218:158-160

Suchman CL (2000) Escape behavior of Acartia hudsonica copepods during interactions with scyphomedusae. J Plankton Res 22:2307-2323

Svensson JE (1992) The influence of visibility and escape ability on sex-specific susceptibility to fish predation in Eudiaptomus gracilis (Copepoda, Crustacea). Hydrobiologia 234:143-150

Tiselius P, Jonsson PR (1990) Foraging behaviour of six calanoid copepods: observations and hydrodynamic analysis. Mar Ecol Prog Ser 66:23-33

Viitasalo M, Kiørboe T, Flinkman J, Pedersen L, Visser WW (1998) Predation vulnerability of planktonic copepods: consequences of predator foraging strategies and prey sensory abilities. Mar Ecol Prog Ser 175:129-142

Yen J (1988) Directionality and swimming speeds in predatorprey and male-female interactions of Euchaeta rimana, a subtropical marine copepod. Bull Mar Res 43:395-403

Yen J (2000) Life in transition: balancing inertial and viscous forces by planktonic copepods. Biol Bull 198:213-224

Yen J, Fields DM (1992) Escape response of Acartia hudsonica (Copepoda) nauplii from flow field of Temora longicornis (Copepoda). Ergeb Limnol 36:123-134

Yen J, Strickler JR (1996) Advertisement and concealment in the plankton: what makes a copepod hydrodynamically conspicuous? Invertebr Biol 115:191-205

Yen J, Lenz PH, Gassie DV, Hartline DK (1992) Mechanoreception in marine copepods: electrophysiological studies on the first antennae. J Plankton Res 14:495-512

Young RE (1983) Oceanic bioluminescence: an overview of general functions. Bull Mar Sci 33:829-845

Zaret TM (1972) Predators, invisible prey, and the nature of polymorphism in the Cladocera (class Crustacea). Limnol Oceanogr 17:171-184

Zaret TM (1980) The effect of prey motion on planktivore choice. In: Kerfoot WC (ed) Evolution and ecology of zooplankton communities. University Press of New England, Hanover, NH, p 594-603

Zaret TM, Suffern JS (1976) Vertical migration in zooplankton as a predator avoidance mechanism. Limnol Oceanogr 21: 804-813

Submitted: July 23, 2001; Accepted: December 17, 2001

Proofs received from author(s): May 22, 2002 